\title{
Prevalensi Gangguan Tidur pada Remaja Usia 12- 15 Tahun di Sekolah Lanjutan Tingkat Pertama
}

\author{
Adelina Haryono, Almitra Rindiarti, Alia Arianti, Anandika Pawitri, Achmad Ushuluddin, \\ Amalia Setiawati, Aditia Reza, Corrie W. Wawolumaja*, Rini Sekartini** \\ Mahasiswa Fakultas Kedokteran Universitas Indonesia, \\ *Departemen Ilmu Kesehatan Anak, Fakultas Kedokteran Universitas Indonesia, \\ **Departemen Ilmu Kedokteran Komunitas, Fakultas Kedokteran Universitas Indonesia
}

\begin{abstract}
Latar belakang. Gangguan tidur dinilai dari gangguan dalam jumlah, kualitas, atau waktu tidur. Gangguan tidur banyak ditemukan pada remaja $(73,4 \%)$, namun belum banyak dilakukan di Indonesia.

Tujuan. Mengetahui prevalensi gangguan tidur pada remaja usia 12-15 tahun di SLTP "X", Kelurahan Jati, Jakarta Timur.

Metode. Studi potong lintang dilakukan terhadap 140 pelajar SLTPN 92 di Kelurahan Jati, Jakarta Timur pada bulan Mei 2009, dengan teknik stratified purposive sampling. Pengambilan data dilakukan menggunakan kuesioner Sleep Disturbance Scale for Children (SDSC) yang diisi secara self-administered oleh orang tua beserta anak di rumah.

Hasil. Prevalensi gangguan tidur didapatkan 62,9\%, dengan gangguan transisi bangun-tidur sebagai jenis gangguan yang paling sering ditemui. Separuh subjek memiliki perbedaan waktu bangun antara hari sekolah dengan hari libur, $72,9 \%$ memiliki perbedaan waktu tidur yang tidak signifikan. Separuh subjek tidur cukup selama hari sekolah, dan $65 \%$ di hari libur. Aktivitas yang menenangkan sebelum tidur dilakukan oleh 73,6\% subjek. Uji kemaknaan menunjukkan hubungan antara gangguan tidur dengan durasi tidur di hari sekolah dan aktivitas di tempat tidur $(p<0,05)$. Tidak ada hubungan antara perbedaan waktu bangun atau tidur hari sekolah dengan hari libur, durasi tidur di hari libur, kebiasaan konsumsi minuman berkafein, dan lingkungan dengan gangguan tidur $(p<0,05)$.

Kesimpulan. Gangguan tidur banyak ditemukan pada remaja usia 12-15 tahun. Sleep Disturbance Scale for Children dapat digunakan sebagai uji tapis dalam mendeteksi gangguan tidur pada remaja. (Sari Pediatri 2009;11(3):149-54).
\end{abstract}

Kata kunci: Gangguan tidur, remaja, sleep disturbance scale for children (SDSC)

\footnotetext{
Alamat korespondensi

DR. Dr. Rini Sekartini, Sp.A(K). Divisi Tumbuh Kembang Pediatri Sosial. Departemen Ilmu Kesehatan Anak FKUI-RSCM. Jl. Salemba no. 6, Jakarta 10430. Telepon: 021-3160622. Fax.021-3913982
}

$\mathrm{F}$ ase remaja adalah fase tumbuh kembang dengan karakteristik terdapat perubahan penting dalam fungsi kognitif, perilaku, sosial, dan emosional sesuai perkembangan 
biologis, serta adanya fungsi dan tuntutan baru dalam lingkungan keluarga maupun sosial. Pada remaja terdapat perubahan dramatis dalam pola tidur-bangun meliputi durasi tidur berkurang, waktu tidur tertunda, dan perbedaan pola tidur pada hari kerja dan akhir pekan. Maka, kualitas tidur remaja juga cenderung berkurang. ${ }^{1}$

Dalam beberapa dekade terakhir, penelitian epidemiologi mengungkapkan bahwa jumlah anak remaja yang mengalami gangguan tidur semakin meningkat. ${ }^{2}$ Penelitian Ohida $\mathrm{dkk}^{3}$ terhadap siswa SLTP dan SMU menunjukkan prevalensi gangguan tidur yang bervariasi mulai dari 15,3\% hingga 39,2\%, bergantung pada jenis gangguan tidur yang dialami. Penelitian yang dilakukan oleh Bruni $\mathrm{dkk}^{4}$ mengenai gangguan tidur dengan menggunakan metode Sleep Disturbances Scale for Children mendapatkan prevalensi gangguan tidur pada populasi kontrol 73,4\%. Di Indonesia, belum ada penelitian epidemiologi yang dilakukan untuk mengetahui gangguan tidur pada remaja.

Gangguan tidur merupakan suatu kumpulan kondisi yang dicirikan dengan gangguan dalam jumlah, kualitas, atau waktu tidur pada seorang individu. ${ }^{5}$ Gangguan tidur pada remaja dipengaruhi berbagai faktor, baik medis maupun non-medis. Faktor-faktor non-medis yang mempengaruhi tidur antara lain jenis kelamin, pubertas, kebiasaan tidur, status sosioekonomi, keadaan keluarga, gaya hidup, dan lingkungan yang berhubungan dengan gangguan tidur. Sedangkan faktor medis yang mempengaruhi tidur antara lain berbagai gangguan neuropsikiatri dan penyakit kronis, seperti asma dan dermatitis atopi. ${ }^{3,6,7}$ Diagnosis gangguan tidur pada remaja sulit ditegakkan, karena keluhan gangguan tidur seringkali tidak disampaikan oleh remaja, selain itu pada usia remaja pola tidur tidak lagi menjadi pusat perhatian orang tua. Oleh karena itu gangguan tidur pada remaja seringkali tidak terdiagnosis dan akhirnya tidak diobati dengan baik. ${ }^{4,8}$

Uji tapis gangguan tidur dapat dilakukan dengan bantuan berbagai metode, salah satunya dengan SDSC. Sleep Disturbances Scale for Children merupakan kuesioner yang diisi oleh orangtua pasien dengan mengingat pola tidur anak mereka dalam keadaan sehat selama enam bulan terakhir. Melalui metode SDSC dapat dideteksi gangguan tidur dan jenis gangguan tidur yang dialami oleh anak usia 6 hingga 15 tahun. Metode SDSC sering digunakan karena prinsip analisis komponen yang kuat, normalitas yang distandarisasi, dan usia yang dipakai sesuai dengan usia subjek yang diteliti. $^{4,8}$

Berdasarkan pola jam sekolah di Indonesia, gaya hidup, dan pola aktivitas remaja di luar jam sekolah, diperkirakan gangguan tidur merupakan masalah yang banyak dialami oleh remaja di Jakarta. Penelitian dilakukan untuk mengetahui pola tidur dan jenis gangguan tidur yang dialami oleh remaja di SLTP, serta faktor-faktor yang berhubungan dengan gangguan tidur.

\section{Metode}

Penelitian dengan desain potong lintang dilakukan pada bulan Mei 2009 di SLTP "Negeri 92" Kelurahan Jati, Jakarta Timur. Sampel penelitian adalah pelajar berusia 12-15 tahun yang tersaring melalui kriteria inklusi dan eksklusi. Pengambilan sampel dilakukan dengan cara stratified purposive sampling. Subjek dibagi menjadi kelompok kelas I, II, dan III. Kuesioner diisi di sekolah dan oleh orang tua masing-masing di rumah. Penilaian gangguan tidur dilakukan dengan menggunakan kuesioner Sleep Disturbances Scale for Children yang dimodifikasi berupa terjemahan ke dalam bahasa Indonesia yang sudah divalidasi dan dinilai realibilitasnya. Data yang terkumpul dilakukan editing, coding, entry, dan verification menggunakan program SPSS 17.0.

\section{Hasil}

Pengumpulan data menghasilkan 140 responden yang memenuhi kriteria inklusi dan eksklusi, participation rate $63,6 \%$. Distribusi data karakteristik responden tertera pada Tabel 1 .

Gangguan tidur didapatkan pada $62,9 \%$ subjek, yaitu subjek dengan skor SDSC lebih dari 39. Sebaran responden berdasarkan klasifikasi gangguan tidur tertera pada Tabel 2. Jenis gangguan tidur yang paling banyak ditemukan adalah gangguan transisi tidurbangun.

Analisis uji chi-square menunjukkan bahwa tidak ditemukan hubungan antara gangguan tidur dengan jenis kelamin maupun dengan pendapatan keluarga. Hubungan didapatkan antara gangguan tidur dengan durasi tidur di hari sekolah $(p<0,05)$, sedangkan tidak 
Tabel 1. Sebaran responden berdasarkan sosio-demografik, pola tidur, kebiasaan konsumsi, dan keadaan lingkungan $(\mathrm{n}=140)$

\begin{tabular}{|c|c|c|c|}
\hline Variabel & Kategori & $\mathrm{n}$ & $\%$ \\
\hline \multirow[t]{2}{*}{ Jenis kelamin } & Perempuan & 98 & 70 \\
\hline & Laki-laki & 42 & 30 \\
\hline \multirow[t]{4}{*}{ Pendapatan keluarga } & Rendah & 79 & 56,4 \\
\hline & Menengah-rendah & 57 & 40,7 \\
\hline & Menengah-tinggi & 4 & 2,9 \\
\hline & Tinggi & 0 & 0 \\
\hline \multicolumn{4}{|l|}{ Kebiasaan tidur } \\
\hline \multirow{2}{*}{ Perbedaan waktu bangun } & Bermakna & 71 & 50,7 \\
\hline & Tidak bermakna & 69 & 49,3 \\
\hline \multirow[t]{2}{*}{ - Perbedaan waktu tidur } & Bermakna & 38 & 27,1 \\
\hline & Tidak bermakna & 102 & 72,9 \\
\hline \multirow{2}{*}{ - Durasi tidur di hari sekolah } & Tidak cukup & 69 & 49,3 \\
\hline & Cukup & 71 & 50,7 \\
\hline \multirow{2}{*}{ - Durasi tidur di hari libur } & Tidak cukup & 49 & 35 \\
\hline & Cukup & 91 & 65 \\
\hline \multirow{2}{*}{ - Kegiatan sebelum tidur } & Tidak mendukung & 37 & 26,4 \\
\hline & Mendukung & 103 & 73,6 \\
\hline - Aktivitas di tempat tidur & $\begin{array}{l}\text { Tidak baik } \\
\text { Baik }\end{array}$ & 126 & 90 \\
\hline Kebiasaan konsumsi & & 14 & 10 \\
\hline \multirow{2}{*}{ Kafein (teh, kopi, soda) } & Ya & 26 & 18,6 \\
\hline & Tidak & 114 & 81,4 \\
\hline \multirow[t]{2}{*}{ - Alkohol } & Ya & 0 & 0 \\
\hline & Tidak & 140 & 100 \\
\hline \multirow[t]{2}{*}{ - Rokok } & Ya & 0 & 0 \\
\hline & Tidak & 140 & 100 \\
\hline Keadaan lingkungan & Ya & 19 & 13,6 \\
\hline \multirow[t]{2}{*}{ Bising } & Tidak & 121 & 86,4 \\
\hline & Tidak mematikan lampu & 52 & 37,1 \\
\hline \multirow[t]{2}{*}{ - Cahaya } & Mematikan lampu & 88 & 62,9 \\
\hline & Bukan ruang tidur & 19 & 13,6 \\
\hline \multirow[t]{2}{*}{ - Lokasi tidur } & Ruang tidur & 121 & 86,4 \\
\hline & Ada & 54 & 38,6 \\
\hline \multirow[t]{2}{*}{ - Co-sleeping } & Tidak ada & 86 & 61,4 \\
\hline & Ada & 64 & 45,7 \\
\hline - Televisi dalam kamar tidur & Tidak ada & 76 & 54,3 \\
\hline
\end{tabular}

ditemukan hubungan antara gangguan tidur dengan durasi tidur di hari libur. Hubungan juga ditemukan antara gangguan tidur dengan aktivitas di tempat tidur. Perbedaan waktu tidur dan bangun antara hari sekolah dengan hari libur, serta kegiatan sebelum tidur tidak memiliki hubungan dengan gangguan tidur (Tabel 3).

Tidak ditemukan adanya hubungan antara gangguan tidur dengan kebiasaan konsumsi kafein. Analisis terhadap kebiasaan merokok dan konsumsi
Tabel 2. Sebaran responden berdasarkan klasifikasi gangguan tidur sesuai SDSC ( $\mathrm{n}=88)$

\begin{tabular}{lcc}
\hline Jenis gangguan tidur & $\mathrm{n}$ & $\%$ \\
\hline Gangguan memulai dan mempertahankan & & \\
tidur & 51 & 58,0 \\
Gangguan pernapasan saat tidur & 44 & 50,0 \\
Gangguan kesadaran saat tidur & 44 & 50,0 \\
Gangguan transisi tidur-bangun & 56 & 63,6 \\
Gangguan somnolen berlebihan & 51 & 58,0 \\
Hiperhidrosis saat tidur & 44 & 50,0 \\
\hline
\end{tabular}


Tabel 3. Hubungan antara kebiasaan tidur responden dengan gangguan tidur $(\mathrm{n}=140)$

\begin{tabular}{lccc}
\hline \multirow{2}{*}{\multicolumn{1}{c}{ Variabel }} & \multicolumn{2}{c}{ Gangguan tidur } & \\
\cline { 2 - 3 } & $\begin{array}{c}\text { Ya } \\
(\mathrm{n}, \%)\end{array}$ & $\begin{array}{c}\text { Tidak } \\
(\mathrm{n}, \%)\end{array}$ & $p$ \\
\hline Kebiasaan tidur & & & \\
Perbedaan waktu bangun & $47(53,4)$ & $24(46,2)$ & 0,407 \\
Perbedaan waktu tidur & $28(31,8)$ & $10(19,2)$ & 0,106 \\
Durasi tidur di hari sekolah & $51(58,0)$ & $18(34,6)$ & 0,008 \\
Durasi tidur di hari libur & $35(39,8)$ & $14(26,9)$ & 0,124 \\
Kegiatan sebelum tidur & $21(23,9)$ & $16(30,8)$ & 0,371 \\
Aktivitas di tempat tidur & $83(94,3)$ & $43(82,3)$ & 0,027 \\
\hline
\end{tabular}

alkohol tidak dapat dilakukan karena tidak ada responden yang merokok ataupun mengkonsumsi alkohol. Hubungan kemaknaan tidak ditemukan antara gangguan tidur dengan faktor lingkungan seperti bising dan cahaya $(p>0,005)$. Lokasi tidur, $c o-$ sleeping, dan keberadaan televisi di dalam kamar tidur juga tidak memiliki hubungan yang bermakna dengan gangguan tidur.

\section{Diskusi}

Uji tapis gangguan tidur pada anak dapat dilakukan dengan berbagai perangkat skrining. Salah satu uji tapis gangguan tidur adalah kuesioner Sleep Disturbances Scale for Chidren (SDSC). Kuesioner SDSC dapat digunakan pada anak dan remaja dengan kisaran usia 6,5 tahun hingga 15,3 tahun. Hasil penelitian menggunakan SDSC menunjukkan prevalensi gangguan tidur $62,9 \%$. Prevalensi lebih rendah dibandingkan dengan penelitian Bruni $\mathrm{dkk}^{4}(73,4 \%)$ yang juga menggunakan metode SDSC, namun terdapat perbedaan rentang usia subjek dan populasi yang digunakan. Jenis gangguan tidur terbanyak $(63,6 \%)$ yang ditemukan adalah gangguan transisi tidur-bangun. Penelitian oleh Bruni $\mathrm{dkk}^{4}$ sebelumnya tidak memberikan informasi mengenai prevalensi masing-masing klasifikasi jenis gangguan tidur dan hanya menentukan nilai rerata total skor masingmasing kategori sebagai nilai batas penegakan diagnosis kategori gangguan tidur yang bersangkutan. Penelitian kami menggunakan batasan nilai rerata yang berbeda karena distribusi data yang tidak normal dan populasi penelitian yang berbeda.
Secara statistik tidak ditemukan adanya hubungan antara jenis kelamin subjek dengan gangguan tidur, akan tetapi terlihat kecenderungan bahwa perempuan memiliki prevalensi gangguan tidur yang lebih besar. Tidak adanya hubungan antara jenis kelamin dan gangguan tidur tidak sesuai dengan penelitian Patten $\mathrm{dkk}^{9}$ menggunakan Teenage Attitudes and Practices Survey, menunjukkan bahwa jenis kelamin perempuan berhubungan dengan gangguan tidur.

Tidak ditemukan adanya hubungan antara tingkat pendapatan keluarga dengan gangguan tidur. Berbeda dengan penelitian Anderson dkk, ${ }^{10}$ dan Stein dkk, ${ }^{11}$ yang menunjukkan bahwa prevalensi rasa kantuk berlebih dan durasi tidur yang pendek pada remaja ditemukan lebih tinggi pada subjek yang berasal dari tingkat sosio-ekonomi rendah. Kami menggunakan variabel dengan cakupan yang lebih luas, yaitu gangguan tidur yang disaring menggunakan kuesioner SDSC, sedangkan pada penelitian Anderson dkk ${ }^{10}$ menggunakan variabel rasa kantuk berlebih dan durasi tidur yang pendek saja.

Kebiasaan tidur yang dinilai dalam penelitian terdiri dari perbedaan waktu bangun, perbedaan waktu tidur, durasi tidur di hari sekolah, durasi tidur di hari libur, kegiatan sebelum tidur, dan aktivitas di tempat tidur. Terdapat hubungan antara durasi tidur di hari sekolah dan aktivitas di tempat tidur dengan gangguan tidur. Hasil menunjukkan tidak terdapat hubungan antara perbedaan waktu bangun ataupun waktu tidur dengan adanya gangguan tidur. Sedangkan penelitian LeBourgeois $\mathrm{dkk}^{12}$ pada remaja di Italia dan Amerika menunjukkan bahwa kebiasaan tidur yang baik, yaitu menjaga jadwal tidur yang stabil dapat mendukung tidur yang baik.

Hasil penelitian menunjukkan subjek dengan durasi tidur di hari sekolah yang kurang mengalami gangguan tidur lebih banyak dibanding subjek yang durasi tidurnya cukup (58,0\%). Penelitian LeBourgeois $\mathrm{dkk}^{12}$ pada remaja di Italia dan Amerika menunjukkan bahwa durasi tidur yang cukup berperan dalam membentuk kualitas tidur yang baik. Mindell dan Owen ${ }^{1}$ dalam buku A Clinical Guide to Pediatric Sleep: diagnosis and management of sleep problem menyebutkan bahwa durasi tidur yang inadekuat sesuai umur merupakan salah satu mekanisme terjadinya gangguan tidur pada anak dan remaja. Penelitian Hansen dkk $^{13}$ menyebutkan bahwa jadwal sekolah menyebabkan remaja kekurangan waktu tidur. 
Durasi tidur dapat cukup, namun dapat terjadi gangguan dalam kualitas tidur atau perubahan jadwal tidur pada hari libur, yaitu tidur lebih larut dan bangun lebih siang dibandingkan hari sekolah. Durasi tidur subjek di hari libur pun cenderung memanjang sampai berlebih.

Sebagian besar subjek yang mengalami gangguan tidur memiliki kebiasaan sebelum tidur yang baik (76,1\%), seperti membaca buku dan mendengarkan musik yang tenang. Hal ini tidak sesuai dengan teori. Penelitian LeBourgeois $\mathrm{dkk}^{12}$ menunjukkan bahwa menghindari aktivitas yang bersifat menstimulasi baik secara fisiologis, kognitif, maupun emosional dapat mengurangi insidens gangguan tidur. Pertanyaan dalam kuesioner yang terlalu luas, yaitu menanyakan apakah anak memiliki kebiasaan tidur yang baik sebelum tidur atau tidak, dapat mengakibatkan salah persepsi dalam menjawab pertanyaan.

Menurut literatur ${ }^{12}$ mengemukakan bahwa konsumsi kafein sebelum tidur mempengaruhi kualitas tidur. Ketidaksesuaian literatur dengan hasil penelitian kami disebabkan ketidakseimbangan proporsi subjek yang mengkonsumsi kafen dengan subjek yang tidak mengkonsumsi kafein, juga disebabkan oleh perbedaan kerentanan seseorang terhadap efek kafein. Tidak ada subjek penelitian yang memiliki kebiasaan konsumsi alkohol ataupun merokok.

Kondisi lingkungan yang diteliti adalah bising, cahaya, lokasi tidur, adanya co-sleeping, dan adanya televisi di kamar tidur. Menurut National Sleep Disorders Research Plan ${ }^{14}$ kualitas tidur dapat dipengaruhi oleh lingkungan sekitar. Namun terdapat perbedaan literatur dengan hasil penelitian ini, dapat disebabkan proporsi subjek dengan kondisi lingkungan yang tidak mendukung jauh lebih sedikit dibandingan subjek dengan kondisi lingkungan baik. Didapatkan juga perbedaan antara hasil penelitian sebelumnya serta literatur dengan hasil penelitian mengenai keberadaan televisi diruang tidur yang dapat mengganggu kualitas tidur. Dari penulisan kami disimpulkan bahwa, 62,9\% remaja mengalami gangguan tidur, dan gangguan transisi tidur-bangun sebagai gangguan tidur terbanyak (58\%). Terdapat hubungan antara kebiasaan tidur, yaitu durasi tidur di hari sekolah dan aktivitas di tempat tidur yang dilakukan sebelum tidur dengan terjadinya gangguan tidur. Tidak terdapat hubungan antara jenis kelamin, gaya hidup seperti kebiasaan konsumsi kafein, bising, cahaya, lokasi tidur, televisi di kamar tidur, cosleeping, serta pendapatan keluarga dengan terjadinya gangguan tidur. Sleep Disturbance Scale for Children dapat digunakan sebagai uji tapis dalam mendeteksi gangguan tidur pada remaja.

\section{Daftar Pustaka}

1. Mindell JA, Owens JA. A Sleep in the pediatric practice. Dalam: Mindell JA, Owens JA, penyunting. A clinical guide to pediatric sleep: diagnosis and management of sleep problems. Lippincott: Williams \& Wilkins; 2003.h.1-10

2. Liu X, Yuyan M, Yizhuo W, Jiang Q, Rao X, Lu X, dkk. Brief report: an epidemiologic survey of the prevalence of sleep disorders among children 2 to 12 years old in Beijing, China. Pediatrics 2005;115:266-8. Didapat dari: http://pediatrics.aappublications.org/cgi/content/full/115/1/ S1/266.

3. Ohida T, Osaki Y, Doi Y, Tanihata T, Minowa M, Suzuki K, dkk. An epidemiologic study of self-reported sleep problems among Japanese adolescents. Sleep. 2004;27:978-85. Didapat dari: http://www.ncbi.nlm.nih. gov/pubmed/15453558. Diunduh pada 12 Mei 2009.

4. Bruni O, Ottaviano S, Guidetti V. The Sleep disturbances Scale for Children (SDSC) construction and validation of an instrument to evaluate sleep Disturbancess in childhood and adolescence. J. Sleep Rrs. 1996;5:251-61. Didapat dari: http://www3.interscience.wiley.com/cgi-bin/ fulltext/119222084/PDFSTART. Diunduh pada 12Mei 2009.

5. Free Health Encyclopedia. Sleep disorders. 2007. Available from URL: http://www.faqs.org/health/Sick-V4/ Sleep-Disorders.html. Diunduh pada 12 Mei 2009.

6. García-Jiménez MA, Salcedo-Aguilar F, RodríguezAlmonacid FM, Redondo-Martínez MP, MonterdeAznar ML, Marcos-Navarro AI, dkk. The prevalence of sleep disorders among adolescents in Cuenca, Spain. Rev Neurol 2004;39:18-24. Didapat dari: http://www. ncbi.nlm.nih.gov/pubmed/15257522.

7. Nutter DA. Sleep disorder: problems associated with other disorders. Updated: Apr 4, 2007. Available from URL: http://emedicine.medscape.com/article/916611-overview. Diunduh pada 12 Mei 2009.

8. Blunden S, Lushington K, Lorenzen B, Ooi T, Fung F, Kennedy D. Are sleep problems under-recognised in general practice. Arch Dis Child. 2004;89:708-12. Didapat dari: http://adc.bmj.com/cgi/content/full/89/8/708. Diunduh pada 13 Mei 2009.

9. Patten CA, Choi WS, Gillin JC, Pierce JP. Depressive 
symptoms and cigarette smoking predict development and persistence of sleep problems in US adolescents. Pediatrics 2000;106:23. Didapat dari: http://pediatrics. aappublications.org/cgi.reprint/106/2/e23. Diunduh pada 12 Mei 2009.

10. Anderson B, Storfer-lesser A, Taylor HG, Rosen CL, Redline S. Associations of executive function with sleepiness and sleep duration in Adoslescent. Pediatrics 2009;123:701-7. Didapat dari: http://pediatrics. aappublications.org/cgi/content/full/123/4/e701.

11. Stein MA, Mendelsohn J, Obermeyer WH, Amromin J, Benca R. Sleep and behavior problems in school-aged children. Pediatrics. 2001;107:1-9. Didapat dari: www. pediatrics.org/cgi/content/full/107/4/e60.
12. LeBourgeois MK, Giannotti F, Cortesi F, Wolfson AR, Harsh J. The relationship between reported sleep quality and sleep hygiene in Italian and American adolescents. Pediatrics 2005 ; 115:257-65. Didapat dari:http://pediatrics. aappublications.org/cgi/content/full/115/1/S1/257.

13. Hansen M, Janssen I, Schiff A, Zee CP, Dubocovich ML. The impact of school daily schedule on adolescent sleep. Pediatrics 2005;115:1555-61. Didapat dari: http://pediatrics. aappublications.org/cgil content/full/115/6/1555.

14. National Sleep Disorders Research Plan. Normal sleep, sleep restriction and health consequences. [cited 2009, May 12]. Didapat dari: http//www.nhlbi.nih.gov/health/ proflsleep/res_plan/section $4 /$ section 4 d.html. 